\title{
Duct-to-mucosa Pancreatojejunostomy is a Safe Technique of Reconstruction after Pancreatoduodenectomy.
}

\author{
Bidhan C Das ${ }^{1}$, Sarwar Sobhan ${ }^{2}$, MAK Azad ${ }^{2}$, Saif Uddin Ahmed ${ }^{2}$, Arif Salam Khan ${ }^{1}$, Zulfiqur Rahman Khan ${ }^{3}$ \\ ${ }^{1}$ Assistant Professor, ${ }^{2}$ Medical Officer, ${ }^{3}$ Professor and Head, Hepato-Biliary-Pancreatic Surgery Division, Department of Surgery, Bangabandhu Shiekh \\ Mujib Medical University, Dhaka, Bangladesh
}

\begin{abstract}
:
Background: A duct-to-mucosa pancreatojejunostomy is technically difficult to perform than Dunking procedure after pancreatoduodenectomy. In contrast, the incidence of anastomotic dehiscence is more in Dunking than duct-to-mucosa procedure. Duct-to-mucosa technique is rarely practiced in our country because of technical difficulties and lack of experiences. Objectives: This study was undertaken to evaluate the safety of duct-to-mucosa procedure in our patients with pancreatoduodenectomy. Methods: We have performed pancreatojejunostomy in 14 consecutive patients using a duct-to-mucosa technique and the result was assessed. Results: No patients developed pancreato-jejunal leakage; however, 6 of 14 patients developed complications not related to operative techniques (wound infections; 3 , jejunal fistula following removal of jejunal feeding tube; 1 , renal dysfunction; 1 , delayed gastric emptying; 1 ) which were managed conservatively. There were no postoperative deaths in the present series and the median postoperative hospital stay was 20.3 days. The follow-up period ranged from 1 to 12 months and all patients are surviving with good health during this period. Conclusion: Pancreatojejunostomy by duct-to-mucosal technique is a safe method of pancreatojejunostomy after pancreatoduodenectomy.
\end{abstract}

Key words: pancreatojejunostomy, duct-to-mucosa technique, anastomotic leak.

[BSMMU J 2013; 6 (1): 54-57]

\section{Introduction:}

Pancreatojejunostomy after pancreatoduo -denectomy is a complicated surgery; the success of which depends on the absence of leakage. There are several anastomotic techniques used to establish the pancreato-jejunonal continuity, among them the most used are the single layer between the pancreatic capsule and the jejunum (Dunking technique $)^{1}$, the pancreatogas-trostomy ${ }^{2}$ in single or double layer and the duct to mucosa technique $e^{3-5}$. Which technique is superior to others still debatable? Few reports have shown that Duct-to-mucosa pancreato-jejunostomy is a superior technique with a very low risk of postoperative pancreatic fistula formation ${ }^{3-5}$, but the technique is difficult and requires an extensive skill to construct the anastomosis. In contrast, other techniques are relatively easy to

Address of correspondence: Dr. Bidhan C Das, Assistant Professor Hepato-Biliary-Pancreatic Division Department of Surgery, BSMMU Mobile: +880-1711889565, E-mail:dbidhan@yahoo.com perform, but the leaking rate is higher ${ }^{3-5}$. Whilst a report show that duct-to-mucosa technique bear the similar incidence of in terms of anastomotic dehiscence when compare to other techniques ${ }^{11}$. For further understanding the fact, we have applied duct-to-mucosa technique after pancreatoduodenectomy for reconstruction in consecutive 14 patients; the result of the procedure is satisfactory. The utility, safety and results of operative technique are described in this study.

\section{Methods:}

Between March 2011 to March 2012, a series of consecutive 14 patients ( 12 males and 2 females) with a mean age of 57 years (range 42 to 74) underwent pancreatodudenectomy for periampu-llary carcinoma $(n=12)$ and carcinoma of head of the pancreas $(n=2)$. Four patients received classical pancreato-duodenectomy (Whipples operation), while the other 10 patients underwent pylorus preserving pancreatoduo-denectomy (PPPD), (Table 1). 
Table-I

Patients, proced ures, status of pancreatic duct and number stitches required for duct-to-mucosa pancreatojejunostomy after pancreatoduodenectomy

\begin{tabular}{|c|c|c|c|c|c|}
\hline Case & Age/Gender & Diagnosis & $\begin{array}{c}\text { Surgical } \\
\text { procedure }\end{array}$ & $\begin{array}{l}\text { Pancreatic } \\
\text { duct diameter } \\
(\mathrm{mm})\end{array}$ & $\begin{array}{l}\text { Number of } \\
\text { stitches }\end{array}$ \\
\hline 1. & $74 / \mathrm{M}$ & periampullary carcinoma & PD & 7 & 8 \\
\hline 2. & $42 / \mathrm{M}$ & periampullary carcinoma & PPPD & 6 & 8 \\
\hline 3. & $55 / \mathrm{M}$ & periampullary carcinoma & PPPD & 10 & 10 \\
\hline 4. & $52 / \mathrm{F}$ & periampullary carcinoma & PPPD & 8 & 8 \\
\hline 5. & $60 / \mathrm{M}$ & $\begin{array}{l}\text { Carcinoma head of the } \\
\text { pancreas }\end{array}$ & PD & 5 & 8 \\
\hline 6. & $65 / \mathrm{M}$ & periampullary carcinoma & PPPD & 6 & 8 \\
\hline 7. & $70 / \mathrm{M}$ & periampullary carcinoma & PPPD & 7 & 8 \\
\hline 8. & $63 / F$ & periampullary carcinoma & PPPD & 8 & 10 \\
\hline 9. & $65 / \mathrm{M}$ & periampullary carcinoma & PD & 5 & 8 \\
\hline 10. & $40 / \mathrm{M}$ & periampullary carcinoma & PPPD & 6 & 8 \\
\hline 11. & $45 / \mathrm{M}$ & periampullary carcinoma & PPPD & 10 & 8 \\
\hline 12. & $62 / \mathrm{M}$ & $\begin{array}{c}\text { Carcinoma head of the } \\
\text { pancreas }\end{array}$ & PD & 5 & 8 \\
\hline 13. & $56 / \mathrm{M}$ & periampullary carcinoma & PPPD & 6 & 8 \\
\hline 14. & $42 / \mathrm{M}$ & periampullary carcinoma & PPPD & 7 & 8 \\
\hline
\end{tabular}

PPPD: Pylorus preserving pancreatoduodenectomy, PD: Pancreatoduodenectomy

After removal of specimen, the distal end of Roux-en-Y loop was brought to pancreatic field through mesocolon behind the transverse colon. A small opening was made by diathermy in the jejunum $2.5-3 \mathrm{~cm}$ away from the closed end at the anti-mesenteric border of distal end of Rouxen-Y loop where the expected anastomosis to be done. A BMI feeding tube of pancreatic duct size was introduced from the side of the distal end of Roux-en-Y loop and was brought through the previously made jejunal opening. The jejunal loop was brought to pancreatic stump. A 4-0 vicryl suture was passed (outside in) from the corner of the pancreatic duct to jejunal opening (inside out). Similar suturing was taken at the opposite corner of pancreatic duct and jejunal opening, and rest 3 to 4 suturing are taken for completing the posterior wall of pancreatojejunal anastomosis (Fig. 1a). Thus the posterior duct-to mucosal anastomosis was completed. The stent tube that already brought through jejunal opening was passed to pancreatic duct. The anterior layer of pancreatojejunal anastomosis was completed by $4-5$ interrupted $4-0$ vicryl suture (Fig.1b). The anterior and posterior duct to mucosal layer was strengthened by anterior and posterior pancreatic capsule-parenchyma to seromuscular layer of jejunum suturing with 3-0 vicryl (Fig.1c).

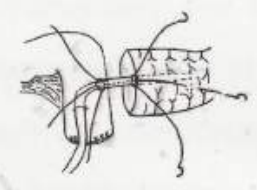

8) Posterior duct-tomucosal layer

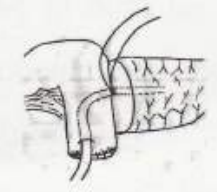

b) Anterior duct-tomucosal layer

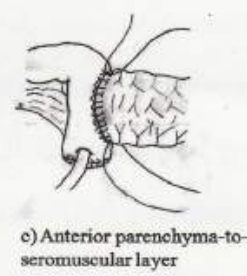

c) Anterior parenchyma-to-
seromuscular layer
Fig-1: Methods of duct-to-mucosal anastomosis

Bilio-enteric anastomosis was then performed on the same jejunal loop, at the distance of approximately 10-15 $\mathrm{cm}$ from the pancreatic anastomosis, using 3-0 vicryl interrupted sutures. Gastro-jejunal anastomosis was performed $40-50 \mathrm{~cm}$ further down the biliary anastomosis in two layers using 3-0 vicryl continuous suture. A jejunal 
in two layers using 3-0 vicryl continuous suture. A jejunal feeding tube was inserted about $30-40 \mathrm{~cm}$ down to gastrojejunal anastomosis for early postoperative enteral nutrition. A silicon drain tube of $24-28 \mathrm{~F}$ size was inserted through a separated stab wound at the right side of the abdomen and kept in right subhepatic region.

All patients were given $800-1500 \mathrm{Kcal}$ energy in the form of $25 \%$ glucose, $10 \%$ aminoacid and fatty acid solution with appropriate fluid and electrolytes in the first 4 to 5 postoperative days through central venous line. Jejunal feeding was started from the $5^{\text {th }}$ to $6^{\text {th }}$ postoperative day when bowel sound returned. Oral feeding was started from $8^{\text {th }}$ to $10^{\text {th }}$ postoperative day. Broad spectrum antibiotics, adequate analgesia, vitamins and minerals supplementation were given according to the needs. Daily electrolytes, $\mathrm{Hb}$, blood sugar and creatinine were measured in the early postoperative period and corrected accordingly. General care (mouth and skin care), breathing exercise, and early mobilizations were given as a routine work.

\section{Results:}

The diameter of the main pancreatic duct in all 14 patients was $5 \mathrm{~mm}$ or more. The median operative time was 4.8 hours ( 3.5 to 6.0 hours), and the median per operative blood loss was $301 \mathrm{ml}(100$ to $640 \mathrm{ml})$. Postoperative recovery from anesthesia was smooth in 13 patients except one who needed ICU support for delayed recovery from anesthesia for 48 hours. There was no perioperative death or major complications like pancreato-jejunal, bilioenteric leakage. Six of 14 patients developed postoperative complications (wound infections; 3 , jejunal fistula following removal of jejunal feeding tube; 1 , renal dysfunction; 1 , delayed gastric emptying; 1). The median postoperative hospital stay was 20.3 days ( 14 to 34 days), (Table 2 ). The follow-up period ranged from 1 to 12 months and all patients are surviving with good health during this period.
Table -II

Outcome of pancreatoduodenectomy

(pancreatojejunostomy was done using duct-to-mucosa technique in all patients)

\begin{tabular}{lc}
\hline Variables & Values \\
\hline Mortality & 0 \\
Morbidity & 6 \\
Pancreato-jejunal fistula & 0 \\
Bilioeneric fistula & 0 \\
Wound infection & 3 \\
Fistula in jejunalfeeding site & 1 \\
Renal dysfunction & 1 \\
Delayed gastric emptying & 1 \\
Postoperative stay (days) & $20.3(14-34)$ \\
\hline
\end{tabular}

\section{Discussion:}

Reconstructive surgery after pancreatoduo-denectomy is a complex procedure. It is composed of pancreatojejunostomy, heap-ticojejunostomy and gastrojejunostomy. Pancreatojejunostomy carries probably the highest risk of failure of all other anastomoses. This may be partly due to the fact that it is an anastomosis between a solid organ and a hollow viscus and to the harmful liquid content which is the pancreatic juice with its enzyme activated by the presence of bile or even by the gut content and microbial flora. Once the anastomosis breaks the mortality rate becomes tremendously high. Total pancreatectomy is sometimes required for saving patients life. If patient survives the total pancreatectomy, quality of life affects severely afterwards. Various types of anastomosis have been developed with an attempt to prevent such disastrous condition, such as 'Dunking technique", duct-tomucosal technique ${ }^{4-5}$, and parachute technique ${ }^{3}$. In addition to techniques, debates are persisted world-wide during pancreatojejunostomy on use of suture materials (non-absorbable / delayed absorbable), methods of suturing (interrupted / continuous), use of stent, lost stent or without stent. The existence of so many descriptions of different techniques which deal with the treatment of pancreatic stump after pancreatoduodenectomy indicate that probably, there is no single one which is clearly superior to the others in terms of dehiscence, fistula 
formation and related deaths ${ }^{6}$. Although the Dunking procedure is easy to perform, anastomotic dehiscence is higher. On the other hand duct-mucosal anastomosis is technically difficult, but leakage rate is lower. Furguson and Wangesteen ${ }^{7}$ were the first to report a new interesting experimental technique for pancreato-jejunal anatomosis, directly approximating the jejunal mucosa to the main paincreatic duct epithelium (duct-to-mucosa) subsequently described by Madden ${ }^{8}$. The incidence of leakage is however different among previous reports with conflicting results $^{9 \cdot 11}$. However several authors reported better results with duct-to-mucosa technique ${ }^{12-13}$ than end to end or end to side Dunking technique ${ }^{11}$. Our result with duct-tomucosa technique is excellent as we didn't face any leakage of pancreato-jejunal anastomosis in consecutive 14 patients. Fortunately, in all cases the main pancreatic diameter was $5 \mathrm{~mm}$ or more and hence the duct-to-mucosal anastomosis was relatively easier. In patients where the pancreatic duct diameter is less than $5 \mathrm{~mm}$, magnifying loops (microsurgical procedure) can be used for performing this anatomosis. Duct-to-mucosa technique in a non dilated pancreatic duct is a more time consuming and demanding technique, necessarily requiring a microsurgical skill, Dunking procedure may be considered as an alternative option to them. Sikora and posner ${ }^{6}$, Marcus et $\mathrm{al}^{14}$, and Suzuki et al ${ }^{15}$ also preferred the selective duct-tomucosa technique in presence of firm fibrotic pancreas with duct diameter of $5 \mathrm{~mm}$ or more; dunking technique in presence of friable pancreas and non dilated main pancreatic duct. Regarding the use of suture materials, types of suturing, use of stenting, although a few studies ${ }^{3,12}$ have, others ${ }^{11,16}$ did not show any significant differences between uses of suture materials, continuous or interrupted suturing, and uses stent or without stent in terms of anastomotic dehiscence.

\section{Conclusion:}

Considering our findings and reported results in the literature it can be concluded that pancreato-jejunostomy by duct-to-mucosal technique is a safe method of pancreatojejunostomy after pancreatoduodenectomy in selected cases in our context; however multicentre rando-mized controlled trials are needed for final comment.

\section{References:}

1. Batignani G, Fratini G, Zuckermann M, Bianchini E and Tonelli F. Comparison of wirsung-jejunal duct-to-mucosa and dunking technique for pancreatojejunostomy after pan-creatoduodenectomy. Hepatobiliary Pancreat Dis int. 2005; $4(3): 450-455$.

2. Hyodo M, Nagai H. Pancreato-gastrostomy (PG) after pancreatoduodenectomy with or without duct-to-mucosa anastomosis for the small pancreatic duct: short- and long-term results. Hepatogastroenterology 2000 Jul-Aug;47(34):1138-41.

3. Okamoto K, Koyama I, Toshimitsu Y, Aikawa M, Okada K, Ueno $\mathrm{Y}$ and Miyazawa M. Duct-to-mucosa pan-creatojejunostomy for small main pancreatic duct by the parachute technique after pancreatoduodenec-tomy.Hepato-Gastro-enterology 2011; 58: 1025-1028.

4. Sugiyama M, Suzuki Y, Abe N, Ueki H, Masaki T, Mori T, et al. Pancreatic duct holder for facilitating duct-to-mucosa pancreatojejunos-tomy after pancreato-duodenectomy. The Am J Surg. 2009; 197: e18-e20.

5. Hosotani R, Doi R, Imamura M. Duct-to-mucosa pancreatojejunos-tomy reduces the risk of pancreatic leakage after pan-creatoduodenectomy. World J Surg 2002; 26: 99-104.

6. Sikora SS, Posner M. Management of the pancreatic stump following pancreato-duodenectomy. Br J Surg 1995; 82: 1590-1597.

7. Ferguson DJ, Wangensteen $\mathrm{OH}$. Experi-mental anastomosis of the pancreatic duct. Ann Surg 1950;132:1066-1074.

8. Madden JL. Technique for pancreato-duodenectomy. Surg Gynecol Obstet 1964;118:247-267.

9. Poon RTP, Lo SH, Fong D, Fan ST, Wong J. Prevention of pancreatic anastomostic leakage after pan-creatoduodenectomy. Am J Surg 2002; 183:42-52.

10. Yeo $\mathrm{Cj}$, Cameron Jl, Sohn TA, Lillemoe KD, Pitt HA, Talamini MA, et al. Six hundred fifty consecutive pancreato-duodenectomies in the 1990; Pathology complications, and outcomes. Ann Surg. 1997; 226: 257-260.

11. Bassi C, Falconi M, Molinari E, Mantovani W, Butturini G, Gumbs $A A$, et al. Duct-to-mucosa versus end-to-side pancreatojejunostomy reconstruction after pancreato-duodenectomy; results of a prospective randomized trial. Surgery 2003; 134: 766-771.

12. Howard JM. Pancreatojejunostomy: leakage is a preventable complica-tion of Whipples resection. J Am Coll Surg 1997; 184:454-457.

13. Mastomoto $\mathrm{Y}$, Fuji $\mathrm{H}$, Miura $\mathrm{K}$, Inoue $\mathrm{S}$, Sekikawa $\mathrm{T}$, Aoyama $\mathrm{H}$, et al. Successful pancreatojejunal anastomosis for pancreatoduodenec-tomy. Surg Gynecol Obstet 1992;175:555-562.

14. Marcus SG, Cohen H, Ranson JH. Optimal management of the pancreatic remnant after pancreatico-duodenectomy. Ann Surg 1995; 221: 635-648.

15. Suzuki Y, Fujino Y, Tanioka Y, Hiraoka K, Takada M, Ajiki T et al. Selection of pancreaticojejunostomy techniques accor-ding to pancreatic texture and duct size. Arch Surg 2002; 137; 1044-1047.

16. Imaizumi T, Hatori T, Tobita K, Fukuda A, Takasaki K, Makuuchi H. Pancreatico-jejunostomy using duct-to-mucosa anas-tomosis without a stenting tube. J Hepatobiliay Pancreat Surg 2006;13:194-201. 